\title{
Philosophic and Esthetic Traditions, Synthesis of Arts in the Artistic Culture of Russia at the Turn of the XIX-XX Century
}

\author{
Andrey Konovalov ${ }^{1, *}$ Liudmila Mikheeva ${ }^{2, a}$ Yulia Gushchina ${ }^{3, b}$ \\ ${ }^{1}$ Director of the Institute of Fine Arts, Moscow Pedagogical State University, Moscow, Russia \\ ${ }^{2}$ Department of General Humanitarian Disciplines, Russian State Specialized Academy of Arts, Moscow, Russia \\ ${ }^{3}$ Likhachev Russian Research Institute for Cultural and Natural Heritage, Moscow, Russia \\ amail: lira19lm@gmail.com \\ ${ }^{b}$ Email: Gushchina.j@gmail.com \\ *Corresponding author. Email: aa.konovalov@mpgu.edu
}

\begin{abstract}
The article tackles the Silver Age of the Russian culture as distinct period in the history of the country. Philosophers and creative community of the turn of the XIX-XX century) considered preservation of common values, fidelity to the humanitarian tradition of the great Russian culture to be their key mission. Synthesis of arts became the underlying principle for the fruitful development of all artistic movements, trends and schools: coexistence of Realism, Modernism and Symbolism was shaping the essence of spiritual quest of philosophers, writers, musicians and artists. Via application of such scientific methods of analysis as comparative-typological, concrete-text and descriptive during preparation of the article, the authors revealed and generalized the investigated facts of art and culture and also utilized complex approach towards analysis of the research materials. Active implementation of the same approach for aggregation of research data resulted in adjustment in comprehension of such phenomenon as tradition/novation interplay and cultural synthesis. It also revealed manifestation of moral maximalism expressed by philosophers and artists within development of the artistic world map.
\end{abstract}

Keywords: Silver Age, Synthesis of arts, Cultural heritage, Worth of a human personality, Russian classical tradition.

\section{INTRODUCTION}

The term Silver Age defines historical and cultural period in the Russian history at the turn of $\mathrm{XIX}-\mathrm{XX}$ century. It is presently widely applied in the sphere of culture, particularly in literature. Though the Silver Age represents a marvelous period of the Russian history, its historic span is limited by an interlude between the reign of Alexander III and the 1920s.

Nevertheless, there is a number of other terms applied to the same period in the development of culture. One of them is Modernism (meaning "modern" in Latin) that sufficiently defines the Silver Age foundational idea of creation of new art in comparison with the classic art. Another term applied to the period is "cultural renaissance of the beginning of the century" that emphasizes the fact that the new art is based on the traditions of classic art and even promotes its revival. I.Yu.Iskrzhitskaya stipulated that "the sheer definition of Russian literature as Silver Age in the period at the turn of XIX-XX century brings forward two in-depth allusions, becoming truly symbolic: Silver Age was regarded as logical successor of the heritage of the Golden Age of the Russian culture as well as expounding the full essence of the biblical prophecy - "And the silver cord will snap..." A.Blok [1].

\section{FIDELITY TO THE TRADITIONS OF HUMANISM}

Enrichment of a personality's inner world and retention of the human aspect despite the 
mechanization of the everyday life were the primary aim of the thinkers at the turn of the century. Acute moral necessity to protect one's own feelings and to promote human values emphasizes the close connection between the cultural renaissance of the beginning of the $\mathrm{XX}$ century with the humanist traditions that date back to the antiquity of the human history.

It is appropriate to present statement of S.P.Dyagilev who was considered to be the key artistic figure at the beginning of the $\mathrm{XX}$ century: "The greatest power of art is its self-orientation, selfsufficiency and, most importantly, its freedom" [2]. Philosophers-idealists also stated the priority of spiritual freedom, the priority of aesthetics over the ethics. The beautiful was absolutized as being crucial for transfiguration of the material world.

\section{PHENOMENON OF ESTHETICISM AND THE ISSUE OF SYNTHESIS}

The concept of "theurgical art", which is linked to the phenomenon of estheticism and the issue of synthesis took shape in the same time period. Tools used in one form of art were borrowed by others: music and literature, pictorial art and poetry. Those turned out to be synthetic pursuits in art: science, philosophy, religion, poetry. Art was freed from stereotypes and traditionalism in terms of normativity. Music was considered to be universal language: one can allude to the literature symphonies of A.Beliy, light and music poem of A. Skryabin "Prometheus", synthesis of decorative, musical and choreographic art in the mixed ballet and opera of non-repertories of S.Dyagilev. A.Beliy stated that "Music reveals to us the mysteries of movement, its essence, that makes the world go round."[3]

The culture of the Silver Age can be truly viewed as Eurasian, as it combined the artistic past of the Russian culture with its holism (historicism, mythopoetics, folklore, religiosity) and perspectives of the future, synthesis of pursuit and artistic conquest of the experience of the West and the East.

Russian Modernism was characterized by synthesis of arts, subordinated to the laws of internal harmony: literature, pictorial art, architecture, decorative and applied arts. This pursuit was based on the surging interest towards mythological perception of the world.

As far as Symbolism is concerned, in addition to the mythological perception of the world it can be distinguished by the compression of visual thinking, metaphoric approach as peculiar artistic way of attainment of reality and mythologization.

Realism as approach towards creative attainment of life and formation of images was based on the consideration of a man as "measure of all things", that was firstly promoted in the antiquity, transmitted through the Divinity of the intellect and intelligence of matter during the period of the Renaissance, found its logical development within the system of positive philosophy and evolution-based model of the development of the world and entered the period of crises at the beginning of the XX century. Development of the artistic culture saw advent of various literary schools, trends, which esthetic variety was propelled by the spiritual pursuits in arts. The contradiction between the traditional and emerging artistic forms was also accompanied by the mutual influence. For instance, realistic method was enriched with the new artistic quality in the form of vicarious reflection of reality.

This was firstly connected with the rethinking of the historical destiny of Russia and its peoples under the new social environment (the time of revolutions and wars, breaking of traditional and established environment). The time put forward global problems: correlation between man and history, eternal and momentary, personality and society, clerisy and people, anarchy and culture, relationship towards classical heritage of the Russian art of the XIX century, and finally, the issue that has become quite acute nowadays, the relationship between man and nature. An artist was required to show clear public stance, as well as mental adaptivity, almost at the level of a prophet, who is capable of identifying enteral and imperishable behind the veil of temporary and movable. Most of this reflection was occurring inside the soul of an artist and therefore Realism at the beginning of the XX century was referred to as "being spiritual".

\section{DIALOGUE OF CULTURES}

The daily practice of the Silver Age creative community members was full of a vivid combination of various artistic properties, synchronous multicultural dialogue. Artistic, philosophic and theological aspects can hardly be distinguished in clear form within the Russian Symbolism; however, they should be viewed holistically.

All of the literary trends, schools and creative artistic associations can be (under certain conditions) designated to Realism or Modernism as they originate in the same epoch and bear inherent traits. 
Artistic pursuits, discussions, gravitation and repulsion, allure towards pan-humanism, importance for the country and peoples, as well as divergence and subsequent concordance - all of these are marked by the peculiar atmosphere of the beginning of the XX century.

Literary art of the beginning of the XX century stood at the boundary between two systems of worldview. It was the time of the shift in the terminus a quo: from the individual features associated with the social environment to a certain cosmological syncretism, to the rethinking, systematization and accumulation of the plethora of knowledge which created the new worldview and, inevitably, the new artistic systems.

The landscape of the struggle between trends and ideas was quite motely and fanciful; idealistic and intuitionistic philosophy, materialism, positivism, Nietzscheanism, pessimism, the so-called "new religious consciousness", Christian existentialism. All those trends were expounded upon in the works of N.Berdyaev, V.Vernadsky, D.Merezhkovsky, I.Minsky, V.Rozanov, N.Fedorov, P.Florensky and L.Shestov. It was not uncommon for the elements of different trends to interwind and mix with each other.

One can outline the key property of the literature of the early XX century: it was its philosophical nature, concentration on those issues of being that had been traditionally known as "eternal" and which became acute at the bifurcation and borderline periods: life and death, good and evil, love, mercy, happiness, time and remembrance. By comprehending one's contemporaries in the everchanging world, the writers strove to reveal the aspects that can elevate a human personality and tried to comprehend the moral landscape that determines the value of a person.

Protagonists in the works of L. Andreev were recalcitrant souls that rioted (distinguishing from the works of M.Gorky for instance) in a different manner. L.Andreev once wrote to M.Gorky in a heated manner, revealing, most likely involuntarily, his own understanding of the human nature "...it is possible to state with a certain degree of sharpness that a man starts at the point when the conflict with the world begins" [4]. Indeed, creative works of L. Andreev have the notion of the "wall" and "rebellion against the wall" as one of the central element of the storytelling. It is worth exploring the world that protagonists of L.Andreev's works cannot accept.

L.Andreev's pessimism is rightfully referred to as "pessimism with heroic mood" [5]. Gorky, however, referred to "cosmic pessimism" of Andreev ("To the stars", "Anathema", "Tsar Hunger", "Savva"). Andreev's pessimism does not equal with inaction, on the contrary, it does not deny the beauty of human actions. Active growth of a personality which spearheaded the attention of writers to this problem at the dawn of the XX century, saw its development in Andreev's works as "nonconformism" of protagonists, who die undefeated ("Life of a Man", "Anathema", "Savva"). Andreev never glorified death. There was the realm of doom, Fatum, however life was not viewed as the road to death.

Global, "enteral" issues were fully and tragically revealed in the works of writer L.D.Rzhevsky (Surazhevsky), whose destiny partially mirrored that of I.A.Bunin (emigration, life far from the Motherland), with main themes and protagonists, autobiographic and associativeness of works, that makes it possible to talk about continuity of artistic method and internal dialogues. Creative works of L.D.Rzhevksy reflect the viability and strength of Realism as artistic method, as it provides for deeper comprehension of the role of a personality through admission of acute issues of that time period, while that personality was placed in different space-time coordinates, understand multi-aspect solutions for the "eternal" problems developed by the writer-realist who represented the "second" wave of emigration of the 1950-1980s. It is important to take into account the fact that both writers were realists and remained loyal to Realism notwithstanding the whirlpool of schools and trends at dawn of the XX century. Fate of the Motherland, its people and a man of the XX century, which were pulled into the turbulent flow of time, which faced the blast of history at the threshold of own house - all these is reflected in the creative works of Bunin and Rzhevsky and makes it feasible to consider their works as legacy with deep interconnection.

\section{MAN AS THE KEY OBJECT OF ATTENTION OF RUSSIAN WRITERS}

It is possible to say that a man was the primary object of depiction in the Russian literature at the beginning of the $\mathrm{XX}$ century, with different writers showing acute interest in this theme, even though they could have been on the opposite sides of the creative pursuits. Realists also aspired to a broader, more comprehensive depiction of a man in his essences and existential aspects. It is here that the writers withdraw from the "external characteristics" [6] and prioritize symbols, signs and "stripping of 
essences (a man in the works of Andreev, Blok, Gorky, Chekhov). Even the names of the protagonists are transformed into generalized symbols: Ivan Ivanovich Ivanov (Chekhov), Man ("Life of a Man" by Andreev), Man (in the eponymous poem by Gorky).

Philosophy of the Silver Age, especially the philosophy of the pan-unity, was emphasizing the richness of essences of Femininity. Peculiarities of the Russian sophiology, the cult of Sophia within the intellectual realm of the Silver Age is exposed via its merge with the Cult of Femininity. The idea of Perpetual Femininity both as feminine foundation in the divine and as metaphysical principle was widely spread among the sophiologs.

Archetypical motive of the woman-mother, saviour, protector, guardian of the enigma of human propagation, provide for characterization of this motive as the dominant one in the Silver Age culture. The concept of femininity in the philosophy of pan0unity was viewed in different aspects: ontological, epistemic, axiological.

\section{CONCLUSION}

Creative view of artists at the beginning of the $\mathrm{XX}$ century was inspired by the vision of personality emancipation. Though it was broadly understood that the harmony between a person and society is hardly achievable, it remained a cherished ideal among the artistic community. The writers of the period experienced revelation by comprehending destiny of the Motherland and its people. Their works were multilayer, synthetic, grand, compressed and laconic, aimed at the quest to reflect the turbulent epoch (with mass movements, revolutionary storms, aspirations and disappointments with the outcomes). Unbundling and unification of literary forces, combined with hardships of creative pursuit (including findings, losses and contradictions, hopes for revival and rebirth of human soul and subsequent disappointments) were the defining the nature of literary, historic and cultural process of the early XX century.

The Silver Age brought forth a particular type of culture which had different reception by the contemporaries. This was the time of intense spirituality and complex social pursuit when the questions of personal dignity and value of a human personality were placed at the foreground of artistic inquiry. A new type of mentality formed during those years (1880s-1920s) that led to the shift in people's attitude towards history, religion, cultural heritage (especially to the "Golden age" of the XIX century). Man and time, personality and freedom, clerisy and culture, revolution, "enteral" questions of existence all these topics dominated spiritual pursuits of each of the Russian artists who also tried to align it with their generation. Writers strove to ringfence their inner connections with the great traditions of the Russian classical literature, explore self-expression of their creative "I" in the new social environment and tried to modify and broaden the boundaries of Realism.

Thus, "modified" Realism co-existed with Symbolism as new form of Romanticism.

Deviating from the dominating concept of the socalled "social" man, the artists concentrated on the sphere of sub-conscious of an individual, refraining from the priority of political thinking in a human consciousness and sharp attention to the religious and philosophical issues of the contemporary existence. It is through aforementioned peculiarities that the Silver Age is revealed as definitely unique period in the evolution of the Russian art.

\section{AUTHORS' CONTRIBUTIONS}

Konovalov A.A. made an important contribution to the comprehension of the "eternal" problems, their tragic reflection in the art of L.D. Rzhevskiy (Surazhevsky), whose destiny, autobiographical nature and associativeness make it possible to imply creative continuity and internal dialogue.

Mikheeva L.N.ocoбoe concentrated attention on co-existence and vivid combination of multiple literary trends, schools and unions - their drift towards panhuman, critical to the country and peoples.

Gushchina Yu.P. concentrated on the vividness of the essence of femininity, uncovering of the peculiarities of the Russian sophiology, underlying emblematic motive of the woman-mother as the dominant theme in the culture of the Silver Age.

\section{REFERENCES}

[1] Iskrzhitskaya I.Yu. Cultural aspects of the literature of the Russian Symbolism. - M.: Russian University Publishing, 1997. - p. 3.

[2] Dyagilev S.P. Complex questions // World of arts. -1889 . - № 1-4. - p. 151.

[3] Beliy A. Forms of art // Beliy A. Symbolism as perception of the world. - M., 1994. - p. 102.

[4] Literary heritage, - V.83, - M., 1971г., p. 494 
[5] History of Russian literature: in 4 volumes. - V. IV. - L., 1983. - p. 336

[6] Unpublished letter of Leonid Andreev (On the creative history of dramas of the period of the Russian revolution) / Introduction, publication and commentary by V.I.Bezzubov // Scientific notes of the Tartusa State University. - Issue. 119. - Tartu, 1962. - p. 386. 